\title{
Light-contingent operant behavior in the turtle'
}

IRWIN M. SPIGEL

TEMPLE UNIVERSITY

\begin{abstract}
Abstraet
The current experiment sought to determine whether the fresh water turtle Chrysemys would demonstrate an incremental response tendency in a panel-press situation for a contingent 2-sec. light. In a repeated measurements design, eight showed a highly significant and consistent increase in response trend during test sessions in darkness over that in room illumination. A significant decrement in panel pressing within darkness sessions was also noted. The possibility that the light-contingent operant behavior facilitates habituation to the test surround is discussed.
\end{abstract}

\section{Introduetion}

A number of investigations, both qualitative and parametric, have demonstrated incremental bar pressing by rats with contingent illumination. These have been recently reviewed by Lockard (1963) who also summarizes theory which has been offered to account for the underlying motivation of this behavior. While earlier study failed to yield such incremental response tendencies with light offset as the contingency (e.g. Barnes \& Kish, 1958), later investigation by Barry \& Symmes (1963) found both light onset and light offset reinforcing when Ss were maintained on a diurnal illumination cycle with equal exposure to light and darkness. Such findings are consistent with the hypotheses that stimulus change (Forgays \& Levin, 1959) or novelty (Berlyne, 1960) are in themselves reinforcing. More recently, Berlyne etal (1964) have shown that in a bar-press situation, the light itself is rewarding and does not mediate the incremental response trend by way of secondary reinforcement or an increase in general excitement or arousal. Lockard also notes that evidence relating to the response levels over time is unclear, many studies showing a decrease while others yield rising functions.

As part of a general program aimed at a broad examination of the effects of stimulus change across classes of organisms, the present experiment sought to determine whether a diurnal reptile-the fresh water turtle Chrysemys - would similarly demonstrate a response

TABLE I

MEAN NUMBER OF PANEL PRESSES FOR THE EIGHT Ss UNDER EACH CONDITION AND PERIOD*

\begin{tabular}{ccccc} 
& \multicolumn{2}{c}{$\begin{array}{c}\text { Light } \\
\text { Half-hour Period }\end{array}$} & \multicolumn{2}{c}{$\begin{array}{c}\text { Dark } \\
\text { Half-hour Period }\end{array}$} \\
\hline Period & 1st & 2nd & 1st & 2nd \\
\hline I (Hours 1 and 2) & 6.00 & 7.00 & 19.38 & 3.38 \\
II (Hours 3 and 4) & 1.62 & 0.38 & 8.88 & 0.62 \\
III (Hours 5 and 6) & 2.25 & 0.12 & 9.38 & 3.75 \\
IV (Hours 7 and 8) & 1.25 & 0.12 & 6.36 & 2.64 \\
\hline
\end{tabular}

* Mean difference of 5.78 significant at $<.05$ level Mean difference of 6.04 significant at $<.01$ level increment in a light-contingent panel-press situation. Earlier study by the author (Spigel, 1964) had shown that climbing and locomotor activity were maintained at a higher level when the illumination underwent change from either light to dark or dark to light after a 40-min. period than when light or darkness remained throughout the 80-min. test session.

\section{Method}

Subjects

Eight male Chrymeys, ages 3 to 4 yrs.as estimated from carapace length ranging from $110 \mathrm{~mm}$ to $140 \mathrm{~mm}$ were employed.

Apparatus

A 12-in x 12-in x 12-in box, open at the top was constructed of plywood. All but one of the interior walls were unpainted. The remaining wall, painted black, contained a white, metal panel, 1-1/2-in $\times$ 2-in mounted $1 / 4$ in from the floor. Pressure on this panel activated a microswitch which turned on a 60-watt light mounted at the top of an adjacent wall, directly above the panel. The light, controlled by an interval timer, remained on for 2 sec. A counter was also activated by each panel press. Overhead room illumination (for sessions given in the lighted condition) measured at the floor of the apparatus was $17-\mathrm{ft}$ candles.

Procedure

In order to qualify for the experiment, a $\mathrm{S}$ was required to press the panel at least once during a 1/2-hr. session in room illumination. This preliminary period preceded all initial test sessions. Eleven turtles had to be run before eight met the criterion. These were then randomly assigned to one of two groups: those starting test hours in light, and those starting in darkness. A repeated measurements design was employed. All Ss received eight 1-hr. sessions every other day, with the first hour given immediately following the 1/2-hr. criterion period. All Ss received hourly sessions alternately in room illumination and darkness. Four Ss received their first trial under room illumination while the remaining four Ss were given their initial test session in darkness. For the purpose of simultaneously evaluating the response trends both within and across sessions under both conditions of illumination, the data for the eight sessions was compressed into four periods. That is, each successive pair of sessions-one in light and one in darkness, or vice-versa-was taken as one period. Period I consisted of each S's first and second hour, and so on through Period IV which comprised the last two hourly sessions. In this way, the effects of order within successive pairs of sessions was counterbalanced. The number of panel presses, and consequent 2-sec. light reinforcements, were recorded for each 1/2-hr. within each hourly session. When not in the ap- 


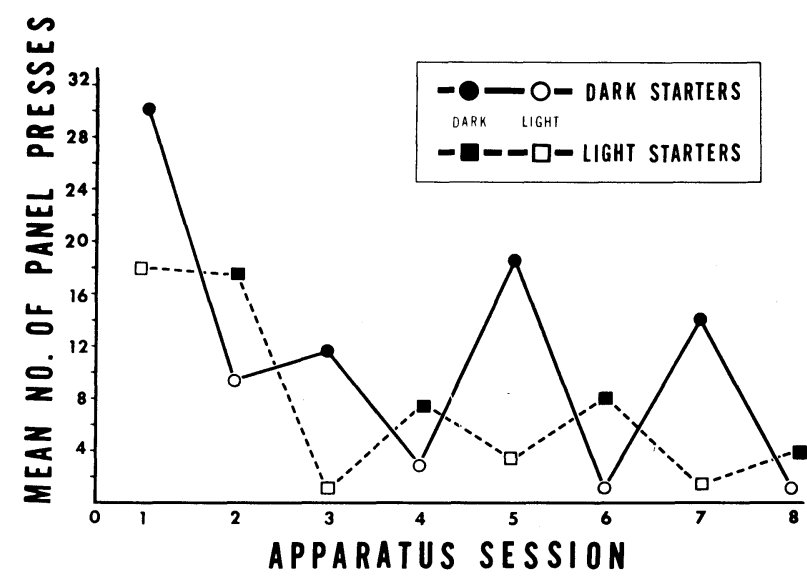

Fig. 1. Total response record for the 8 Ss over the 8 sessions. Half the Ss had their first hour in light and the remainder started in darkness. Records of these sub-groups are plotted separately. paratus, Ss were maintained in glass tanks with 1-in water level in constant room illumination measured at $2.36 \mathrm{ft}$ candles at the water level.

\section{Results}

Half-hr. criterion period panel presses for the four Ss which started in darkness were $4,9,1$, and 9 respectively; and for the Ss given room illumination for their initial test session, criterion period responses totalled 5, 20, 2 and 2. A Mann-Whitney U-test indicated that the difference between these scores was not statistically significant.

Table 1 shows the mean number of panel presses for the eight Ss for each $1 / 2 \mathrm{hr}$., under each condition of the experiment. The records of the dark-starting and lightstarting subgroups are plotted separately in Fig. 1 which contains the total response record of all Ss over the eight test sessions.

The analysis of variance for the 1/2-hr. panel-press totals of all Ss for the entire experiment yielded highly significant $\mathrm{F}$ ratios for periods, 1/2-hr. illumination condition $(8.15 ; \mathrm{df}=3 / 112 ; 20.00 ; \mathrm{df}=1 / 112 ; 18.42 ; \mathrm{df}=$ $1 / 112 ; \mathrm{p}<.01)$. The interaction of $1 / 2-\mathrm{hr}$. and illumination $(F=8.81$; $d f=3 / 112)$ was also significant at less than the .01 level, while the other second-order interactions yielded non-significant $\mathbf{F}$ ratios. The triple interaction of periods $\times 1 / 2-\mathrm{hr} . \mathrm{x}$ illumination yielded an $F$ ratio of $3.95(\mathrm{df}=3 / 112 ; \mathrm{p}<.05)$.

\section{Diseussion}

The significantly greater number of presses for 2-sec of light during the sessions in darkness over the number recorded in room illumination indicates that the performance trend in the turtle is, superficially at least, similar to that obtained for the rat, although at a greatly reduced response level. When the first 1/2-hr. totals are compared for each period, the response level for Ss in dark sessions is never less than three times that for sessions in room illumination. The consistency of this performance pattern is emphasized by the regularity with which the curves in Fig. 1 cross one another from session to session. While there appears to be a decrement in response trend both within and across sessions, as indicated by the significance of the $F$ ratios for $1 / 2-h r$. and periods, this warrants further scrutiny. The within-sessions decrement, as suggested by the significant triple-interaction, is quite pronounced for Ss run in darkness in all four periods, but not in the sessions conducted in room illumination. Although the absence of appreciable decrement under this condition may be attributed largely to the considerably reduced response level generally observed under illumination, a small increase was obtained in the mean performance recorded for the first period. In all cases, the greater reduction in response level occurred between Period I and II.

Taken together, these results suggest that although there may be some intrinsic reward properties of light onset-or of change or novelty provided by the light-another possibility exists in the case of Chrysemys. Previous study of this species has revealed that most Ss become highly excited in new surrounds and especially abhor walled confinement (Spigel, 1964b). It is possible, therefore, that a state of arousal occasioned by the transfer to the test environment is somewhat reduced by visual information obtained during the brief light onsets. This suggestion is supported by the greater decremental response trend within sessions given in darkness. With the accumulating light-on time, habituation to the surroundings may be expected to yield a reduced tendency to respond.

The possibility that Ss are simply more active in darkness, and thus more apt to press the panel, is rendered less likely by the findings of an earlier study (Spigel, 1964a). The data at that time revealed that while general activity in a walled enclosure is not significantly different for Ss in light or darkness for an initial 40-min. period, climbing and locomotion drop to near zero for turtles kept in darkness during a successive 40-min. period. In the current experiment, however, panel-pressing remained significantly greater for Ss during their darkness sessions over all four periods.

Since it is more than likely that different classes of organisms may yield similar data that is, however, differentially motivated, the possibilities noted here for Chrysemys will receive continued investigation.

\section{References}

Barnes, G. W., \& Kish, G. B. On some properties of visual reinforcement. Amer. Psychologist, 1958, 13, 417. (Abstract)

Barry, H., \& Symmes, D. Reinforcing effects of illumination change in different phases of the rat's diurnal cycle. J. comp. physiol. Psychol., 1963, 56, 117-119.

Berlyne, D. E. Conflict, arousal and curiosity. New York: McGrawHill, 1960.

Berlyne, D. E., Salapatek, P. H., Gelman, R. S., \& Zener, S. L. Is light increment really rewarding to the rat? J. comp. physiol. Psychol., 1964, 58, 148-151.

Forgays, D. G., \& Levin, H. Discrimination and reversal learning as a function of change of sensory stimulation. J. comp. physiol. Psychol., 1959, 52, 191-194.

Lockard, R. B. Some effects of light upon the behavior of rodents. Psychol. Bull., 1963, 60, 509-529.

Spigel, I. M. Effect of drugs and illumination change on activity in turtle. Psychol. Rec., 1964a, 14, 305-310.

Spigel, I. M. Learning, retention and disruption of detour behavior in the turtle. J. comp. physiol. Psychol:, 1964b, 57, 108-112.

\section{Note}

1. This research was supported by Grant MH-08679 from the United States Public Health Service. 